\title{
Molecular Catalysis Science: Nanoparticle Synthesis and Instrument Development for Studies under Reaction Conditions
}

\author{
Elad Gross ${ }^{\#}$ and Gabor A. Somorjai* \\ Lawrence Berkeley National Laboratory, 1 Cyclotron Rd., Berkeley, CA, Department of \\ Chemistry, University of California, Berkeley, CA \\ ${ }^{\#}$ Current address: Institute of Chemistry, The Hebrew University of Jerusalem, Israel \\ e-mail: somorjai@berkeley.edu
}

\section{Keywords:}

Heterogeneous catalysis, in-situ spectroscopy, SFG vibrational spectroscopy, X-ray spectroscopy, IR spectroscopy

\begin{abstract}
The synthesis of architecturally-designed catalytic nanostructures and their in-situ characterization under reaction conditions enable the development of catalysts with improved stability, reactivity and products selectivity. Throughout this review paper we will explore three recent reports that demonstrate the invaluable synergetic impact of combining synthesis, catalysis and in-situ spectroscopy for catalysts development. In the first example, products selectivity in 1,3 butadiene hydrogenation reaction was tuned by employing size-selected Pt nanoparticles as catalysts. SFG vibrational spectroscopy measurements uncovered the mechanism that induced the size dependent selectivity. The important role of metal/metal-oxide interface during $\mathrm{CO}$ oxidation reaction is demonstrated in the second part of this review paper. In-situ synchrotron sourced X-ray spectroscopy correlated between the oxidation state of the metal-oxide support and its impact on the catalytic reactivity of supported Pt nanoparticles. In the third example, dendrimer encapsulated $\mathrm{Au}$ nanoparticles were used as catalyst for cascade reactions which was previously catalyzed by homogeneous catalysts. Reactants into products
\end{abstract}


evolution and the oxidation state of catalytically active Au nanoparticles within the flow reactor were mapped with micrometer-sized IR and X-ray beams. These three examples demonstrate the important role of colloidal synthesis and in-situ spectroscopy measurements for in-depth analysis of structure-reactivity correlations.

\section{Introduction}

This review paper is dedicated to the memory of Haldor Topsoe, a giant in the field of catalysis. His understanding of the importance of the science as well as the technology development of catalytic processes set the example for others. His remarkable insight put his stamp on the field during past decades up to the present.

During the last few decades there have been tremendous developments in catalysis research that shifted the research focus from studying simplified model-systems into analysis of more realistic catalysts under reaction conditions. The main developments that initiated this progress were: (i) well-controlled synthesis of catalytic nanostructures [1-5] and (ii) advanced instrumentation for in-situ characterization of catalytic processes under reaction conditions [6-12].

\subsection{Development of model catalytic nanostructures}

The development of well-controlled, simplified, catalytically-active nanostructures which mimic the properties of industrial catalysts was conducted in two different routes. In the first approach, metallic nanoparticles were deposited within a UHV (Ultra-High Vacuum) environment on a single crystal coated with a thin layer of metal-oxide [5, 13-15]. The UHV conditions enabled the preparation of well-defined oxide surfaces and size controlled nanoparticles within a clean environment. Following this approach, different studies have demonstrated the impact of nanoparticle's size and shape $[5,13,16-18]$ on the catalytic properties of the nanoparticles. Other UHV studies emphasized the impact of metal/metal-oxide interface and suggested that this interaction is the main reason for the enhanced reactivity $[19,20,24]$.

One of the well-studied examples in this field was the size-dependent reactivity of oxidesupported $\mathrm{Au}$ nanoparticles towards $\mathrm{CO}$ oxidation reaction [17, 18]. A variety of 
spectroscopic measurements were conducted to uncover the reasons for this unique reactivity [5, 21-23]. For example, it was demonstrated that $\mathrm{CO}$ oxidation rate can be enhanced by up to three orders of magnitude following the deposition of 1-3 nm Au nanoparticles on $\mathrm{MgO}$ surfaces [42-43]. DFT calculations indicated that while supporting $\mathrm{Au}_{8}$ clusters on defect-rich $\mathrm{MgO}$, an electronic charge is transferred from the metal-oxide support to the clusters. The combination of electron-rich Au clusters and high destiny of oxygen vacancies on the $\mathrm{MgO}$ surface facilitate $\mathrm{O}_{2}$ dissociation at the $\mathrm{Au}-\mathrm{MgO}$ interface and enhance the $\mathrm{CO}$ oxidation rate $[15,18]$.

A different approach utilized the knowledge and capabilities of colloidal synthesis for preparation of size and shape controlled catalytically active nanoparticles [1, 3, 25-28]. During the colloidal synthesis, different ligands stabilize the nanoparticles and direct their morphological properties. In this approach, the adsorption of ligands on the metal surface provides high control over the clusters properties but also lowers the number of accessible catalytic sites. Different methods were used in order to remove the ligands and minimize their impact on the catalytic reactivity [29-31]. It was recently demonstrated that by using oxygen plasma treatment most of the surface-adsorbed ligands can be removed without changing the structure of the catalytically active nanoclusters [32]. For example, size controlled Pt nanoparticles were deposited on $\mathrm{TiO} 2$ surface and tested as catalyst in furfural hydrogenation reaction. In order to increase the metal-support interactions the organic ligands were removed by oxygen plasma treatment. It was obtained that following this treatment; the formation rate of furfuryl-alcohol was enhanced by 50 fold, when compared to $\mathrm{SiO}_{2}$ supported nanoparticles, in which the support is catalytically inert. SFG (Sum Frequency Generation) vibrational spectroscopy measurements indicated that reactants adsorption on the $\mathrm{TiO}_{2}$ surface modified the products selectivity due to strong interaction between the oxide surface and the furfural's carbonyl group [32].

\subsection{Advanced instrumentation for in-situ characterization of catalytic processes}

Development of spectroscopic tools which are capable of in-situ characterization of catalytic processes enable to analyze the properties of catalysts under reaction conditions. High pressure STM (Scanning Transmission Microscope) was applied to study the 
structural changes of catalytic surfaces $[33,34]$. A variety of vibrational spectroscopy methods were utilized to follow the reactants to products transformation $[35,36]$. Among these methods are surface sensitive techniques such as SFG (Sum Frequency Generation) vibrational spectroscopy [32, 37] and PM-IRAS (Polarization Modulation Infrared Reflection Absorption Spectroscopy) [38, 39] that detect active intermediates during catalytic reactions. Time resolved IR spectroscopy measurements analyze the kinetic properties of catalytic reactions $[40,41]$ while IR microspectroscopy can track the spatial distribution of reactants and products within the catalyst [42-44].

The expansion of synchrotron based X-ray spectroscopy techniques provides effective tools to study the dynamic electronic properties of catalysts under reaction conditions. HP-XPS (High Pressure X-Ray Spectroscopy), EXAFS (Extended X-ray Absorption Fine Structure) and NEXAFS (Near Edge X-ray Absorption Fine Structures) spectroscopy measurements detect the oxidation state, coordination number and composition of catalysts [45, 46]. High spatial resolution XRD (X-Ray Diffraction) and EXAFS microspectroscopy along with X-ray tomography measurements tracked the dynamic changes in the structure and composition of catalysts [47-50]. These in-situ measurements demonstrated that the catalytic surface is dynamic and its structure, composition and electronic properties can be widely modified under reaction conditions. The dynamic nature of catalysts further emphasizes the importance of in-situ spectroscopy measurements for in depth analysis of catalytic processes.

In this review, we will focus on three casestudies that demonstrate the powerful capabilities gained by combining synthesis of well-defined nanostructures, their application as catalysts and in-situ spectroscopy of the catalytic reaction.

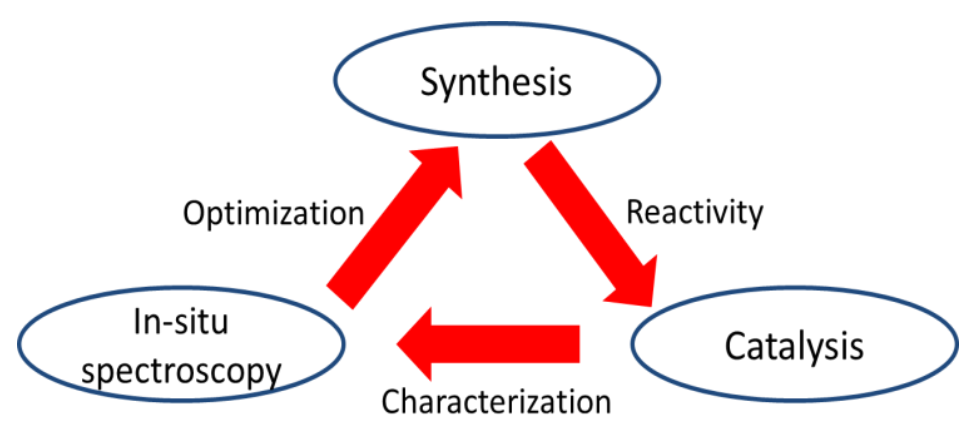

Fig. 1: Combining synthesis of nanoparticles, reactivity measurements and in-situ spectroscopy for characterization and optimization of the catalytic properties of catalysts 
These examples show that in-situ spectroscopy measurements are crucial for the analysis of catalytic processes and for optimization of catalysts (Fig. 1).

In the first example, the structure-reactivity correlations of catalytically active $\mathrm{Pt}$ nanoparticles toward hydrogenation of 1,3 butadiene were studied. Different reaction intermediates were detected by in-situ SFG vibrational spectroscopy by changing the nanoparticles size [51]. In the second example, a variety of mesoporous metal-oxides supports were prepared and tested as catalysts for $\mathrm{CO}$ oxidation reaction, with and without the addition of $\mathrm{Pt}$ nanoparticles [52]. The correlation between the reaction rates and oxidation state of the metal-oxide support were analyzed with in-situ synchrotronbased NEXAFS and HP-XPS. In the third example, highly oxidized $\mathrm{Au}$ nanoparticles were packed in flow reactor and used as catalyst toward cascade reactions that were previously activated by homogenous catalysts [42]. The combination of in-situ IR and Xray micro-spectroscopy tracked the reactants into products evolution and the oxidation state of the catalyst within the flow microreactor. These measurements correlated between the oxidation state of the catalyst along the flow reactor and its catalytic reactivity and selectivity.

\section{Molecular catalysis science: The combination of synthesis, spectroscopy and catalytic reactivity}

\subsection{The impact of the size of $P t$ nanoparticles on the products selectivity in hydrogenation of 1,3 butadiene}

In many catalytic processes the products distribution can be modified by changing the size of catalytically active metallic nanoparticles $[53,54]$. The size dependent selectivity is obtained due to changes in the geometric and electronic properties of the nanoparticle as its size is decreased below $10 \mathrm{~nm}$ [55]. Geometric effects include the size dependence distribution of kinks, steps and terrace sites which are exposed on the metal surface and are highly active during the catalytic process. Electronic effects indicate the changes in the location of the d-band center which is correlated to the interaction between the metal surface and adsorbate molecules [56]. Different studies have demonstrated that product distribution can be tuned by modifying the clusters size in the range of 1-10 nm. In this 
size regime, small changes in the clusters size would have an immediate impact on both its electronic and geometric properties [57, 58].

In order to understand the influence of nanoparticles' size on the reaction mechanism, surface-adsorbed intermediates were analyzed by Sum Frequency Generation (SFG) vibrational spectroscopy $[32,37]$. In this study, polyhedral Pt nanoparticles in the size range of 1-7 nm were synthesized using polyol methods and capped with PolyVinylPyrrolidone (PVP) ligands to prevent clusters aggregation. Pt clusters with different sizes were synthesized by changing the reaction temperature and the amount of PVP and Pt precursor. The colloidal synthesis enabled the formation of Pt nanoclusters with narrow size distribution of up to $\pm 25 \%$ (Fig. 2). The different clusters were then tested as catalysts toward the hydrogenation reaction of 1,3 butadiene (1,3-BD) (Fig. 3a.).

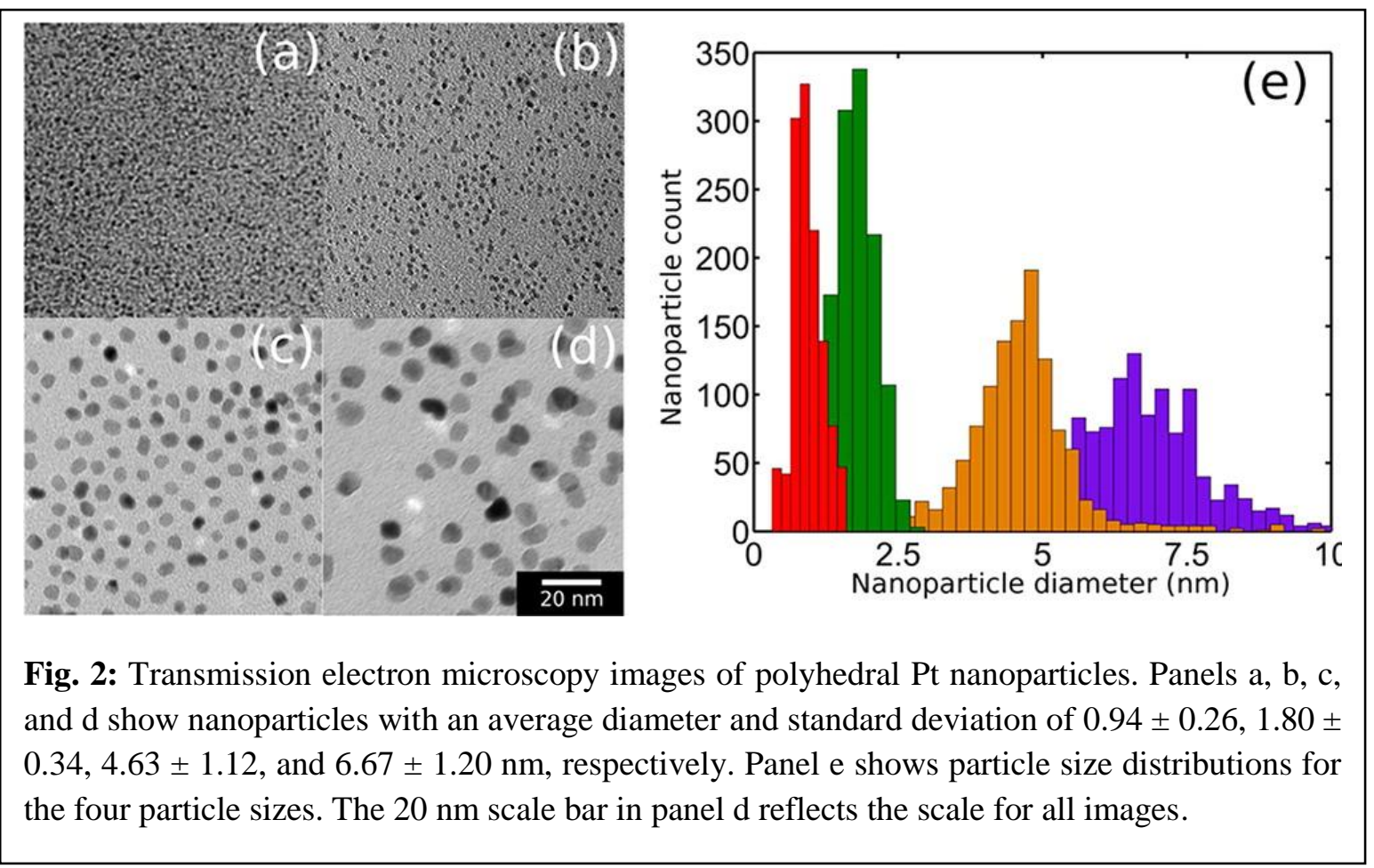


Partial hydrogenation of 1,3-BD can lead to the formation of three isomers: cis 2-butene, trans 2-butene and 1-butene. Saturated n-butane product can be formed as well by the complete hydrogenation of the reactant. The products distribution as function of $\mathrm{Pt}$ nanoparticles size is demonstrated in Fig. 3b. The catalytic measurements were performed at $75^{\circ} \mathrm{C}$ with 10 torr of 1,3-BD, 100 torr of $\mathrm{H}_{2}$ and 650 torr of balancing He. The selectivity was calculated according to the products formation at conversion rate of less than $10 \%$.

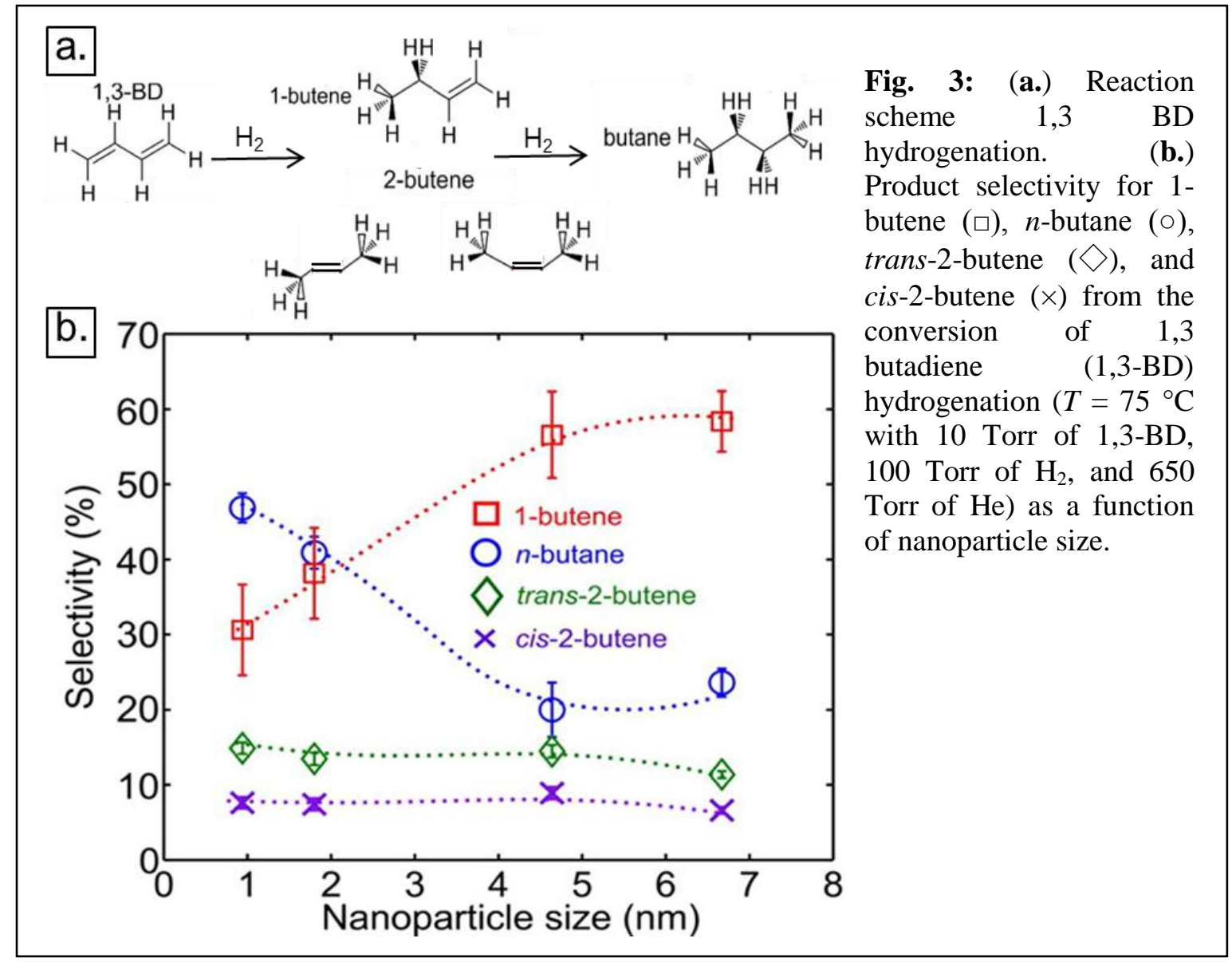

The products distribution show high dependence in clusters size, indicating that this catalytic reaction is indeed structure sensitive. Increased selectivity toward full hydrogenation products was detected as the particles size decreased. For clusters size above $4 \mathrm{~nm}$ the main products were butene isomers. Similar product distribution was measured with $\operatorname{Pt}(111)$ and $\operatorname{Pt}(100)$ single crystals which showed up to $90 \%$ selectivity toward the unsaturated butene isomers products [59]. By decreasing the Pt nanoparticles size below $2 \mathrm{~nm}$ the ratio between partial to full hydrogenation products was modified to $2: 3$. These results indicate that products selectivity can be tuned by up to 6 fold simply by 
changing the nanoparticles size. The similarity in products selectivity of large Pt nanoparticles and $\mathrm{Pt}$ single crystals indicate that at this size regime the catalytic properties of the nanoparticles are similar to that of bulk Pt.

The size-dependent selectivity specify that there are inherent differences in the reaction pathways for 1,3-BD hydrogenation on Pt nanoparticles with various sizes. To elucidate the observed selectivity differences, in-situ SFG vibrational spectroscopy was employed under reaction conditions to monitor the reaction intermediates as function of clusters size (Fig. 4).

SFG vibrational spectroscopy is a surface sensitive technique that exclusively probes molecules at the interface. The analysis of molecules that reside at the solid-gas interface provides a unique capability to probe the most stable long-lived intermediates. The SFG signal was formed by spatially and temporally overlapping a visible beam $(532 \mathrm{~nm})$ and a tunable IR (2680-3180 $\mathrm{cm}^{-1}$ ) beam at the surface of silica prism (Fig. 4b). Pt nanoparticles were deposited on the surface of the prism which capped the reaction cell. The SFG signal was induced from the z-component of adsorbate molecules that reside at the solid-gas interface, sensitive both to the concentration and orientation of the interfacial species.

The vibrational spectra that were detected during 1,3-BD hydrogenation reaction are shown in Figure 4a. Blue circles and dashed red lines indicate the average and standard deviation over nine SFG spectra, respectively, while the solid black line represents the best-fit model spectra. The SFG spectra were correlated to the catalytic selectivity and indicated that the intermediates formed with small $(0.9$ and $1.8 \mathrm{~nm})$ nanoparticles are different than that of the large (4.6 and $6.7 \mathrm{~nm})$ nanoparticles. 


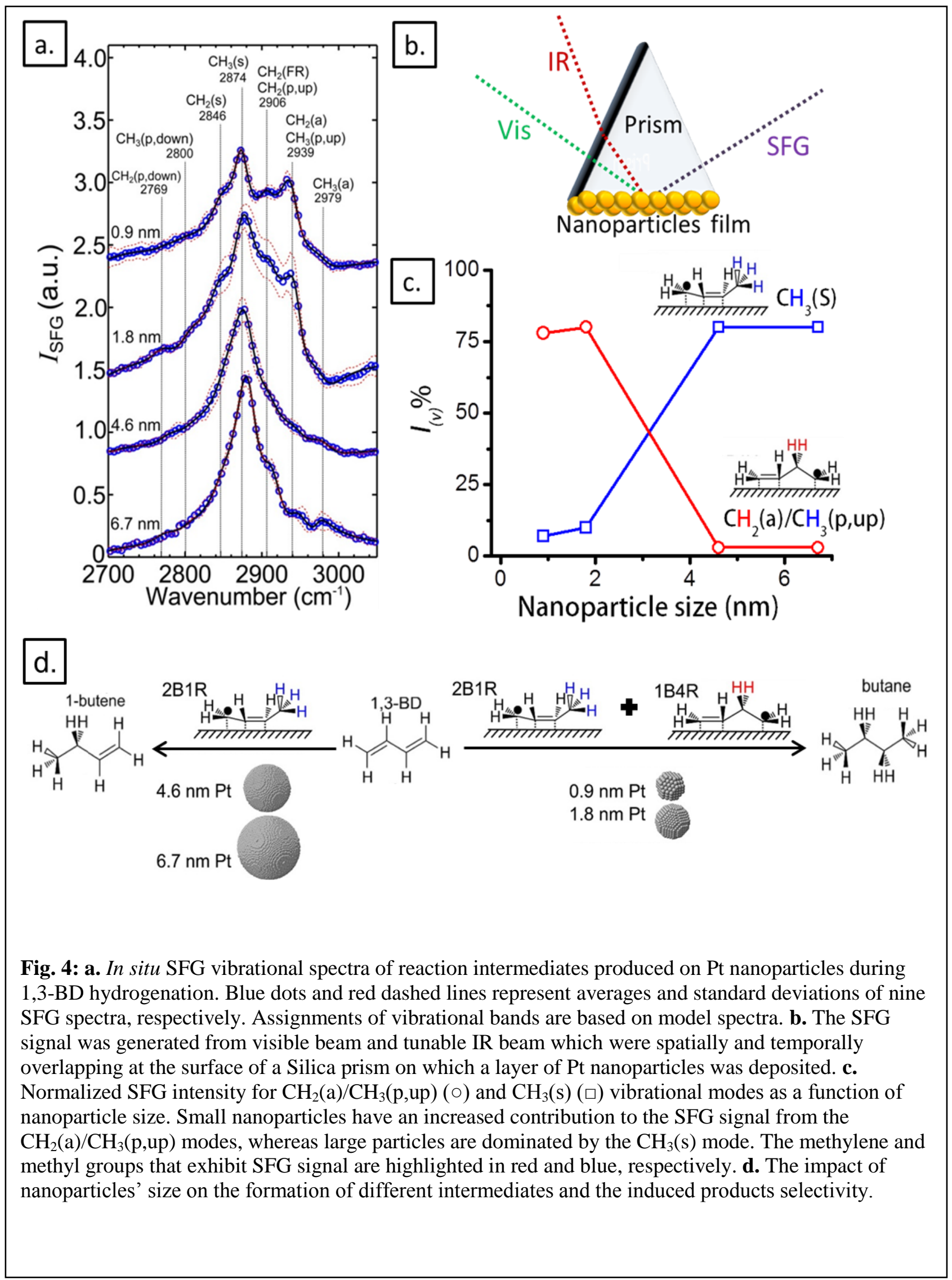


The SFG spectra of the larger nanoparticles exhibit a dominant peak at $\sim 2878 \mathrm{~cm}^{-1}$, which was assigned to the symmetric stretch of $\mathrm{CH}_{3(\mathrm{~s})}$. In addition, a shoulder peak was located at 2906 and $2979 \mathrm{~cm}^{-1}$ which corresponds to methylene stretch $\left(\mathrm{CH}_{2(\mathrm{FR})}\right)$ and the asymmetric stretch of $\mathrm{CH}_{3}\left(\mathrm{CH}_{3(\mathrm{a})}\right)$, respectively. Four bands construct the primary SFG spectral features of the small nanoparticles. The four peaks (2846, 2874, 2906 and 2939 $\mathrm{cm}^{-1}$ ) were assigned to the symmetric stretch of $\mathrm{CH}_{2}\left(\mathrm{CH}_{2(\mathrm{~S})}\right)$ and $\mathrm{CH}_{3}\left(\mathrm{CH}_{3(\mathrm{~S})}\right)$, the fundamental methylene stretching mode $\left(\mathrm{CH}_{2(\mathrm{FR})}\right)$ and methylene asymmetric stretch $\left(\mathrm{CH}_{2(\mathrm{a})}\right)$.

In order to better illustrate the catalytic and spectroscopic correlations, normalized SFG intensities of the $\mathrm{CH}_{2(\mathrm{a})} / \mathrm{CH}_{3(\mathrm{p} \text {,up) }}$ and $\mathrm{CH}_{3(\mathrm{~S})}$ as function of the nanoparticles size were plotted (Fig. 4c). The increase in $\mathrm{CH}_{2(\mathrm{a})} / \mathrm{CH}_{3(\mathrm{p} \text {,up) }}$ ratio with small nanoparticles provides an indication for the accessible route leading to formation of saturated butane product. SFG signals indicate the development of both 1-buten-4-yl and 2-buten-1-yl radicals on small nanoparticles, which provide favorable pathways for n-butane formation.

It was previously-demonstrated that small nanoparticles exhibit an increase in the density of step and corner sites at the expense of terrace sites [55-56]. The high density of atoms with lower coordination number will shift the d-band center location and increase the number of empty anti-bonding states. As a consequence, reactant-metal interactions will increase. Moreover, a higher d-band center makes the surface more reactive by lowering the transition state energy of reactant molecules, uncovering additional pathways toward products formation $[15,18]$.

High density of low-coordination sites on small nanoparticles will also modify the binding geometry of reactants and intermediates on the metal surface. These changes in the surface structure will give rise to the formation of different intermediates which could not be obtained on bigger nanoparticles or on terrace sites. The in-situ SFG vibrational spectroscopy measurements indicated that 0.9 and $1.8 \mathrm{~nm} \mathrm{Pt}$ nanoparticles provide modified adsorption sites (e.g., low coordination sites) that facilitated H-insertion both to the internal carbon and terminal carbon. The 4.6 and $6.7 \mathrm{~nm}$ Pt nanoparticles favor $\mathrm{H}$ insertion at the terminal carbon, as also observed on Pt bulk materials (Fig. 5d). These results suggest that the presence of low-coordination sites promotes $\mathrm{H}$-insertion at the 
internal carbon (in addition to the external carbon), which are not obtained in bigger nanoparticles, either due to electronic or geometric effects.

\subsection{Enhanced CO-oxidation rate at the interface of mesoporous oxide and $\mathbf{P t}$}

nanoparticles: It was widely demonstrated that the catalytic reactivity of metallic nanoparticles can be enhanced following their deposition on designated metal oxide supports $[19,20,32]$. Different studies have indicated that the development of strong metal-support interactions (SMSI) increase the catalytic reactivity by either tuning the electronic properties of the metal [27, 60] or due to the formation of a highly active metal/metal-oxide interface [21]. The exact mechanism that governs these catalytic reactions was not fully understood, due to limited insight of the metal/metal-oxide interface during the catalytic reaction. Synchrotron based measurements make it possible to study the structure and composition of complex catalytic systems under reaction conditions.

A variety of mesoporous oxides $\left(\mathrm{Co}_{3} \mathrm{O}_{4}, \mathrm{NiO}, \mathrm{MnO}_{2}, \mathrm{Fe}_{2} \mathrm{O}_{3}\right.$ and $\left.\mathrm{CeO}_{2}\right)$ were synthesized and loaded with size controlled Pt nanoparticles to investigate the metal/metal-oxide interface effect on $\mathrm{CO}$ oxidation reaction rate. The mesoporous oxides were prepared through hard template approach [61]. In this method, mesoporous silica was used as a template on which a specific metal-oxide was impregnated. The mesoporous silica was then removed by base, forming the pure mesoporous metal-oxide replica (Figure 5). Following the formation of crystalline metal-oxide, PVP capped Pt nanoparticles with an average diameter of $2.5 \mathrm{~nm}$ were incorporated within the channels of the mesoporous oxide. 


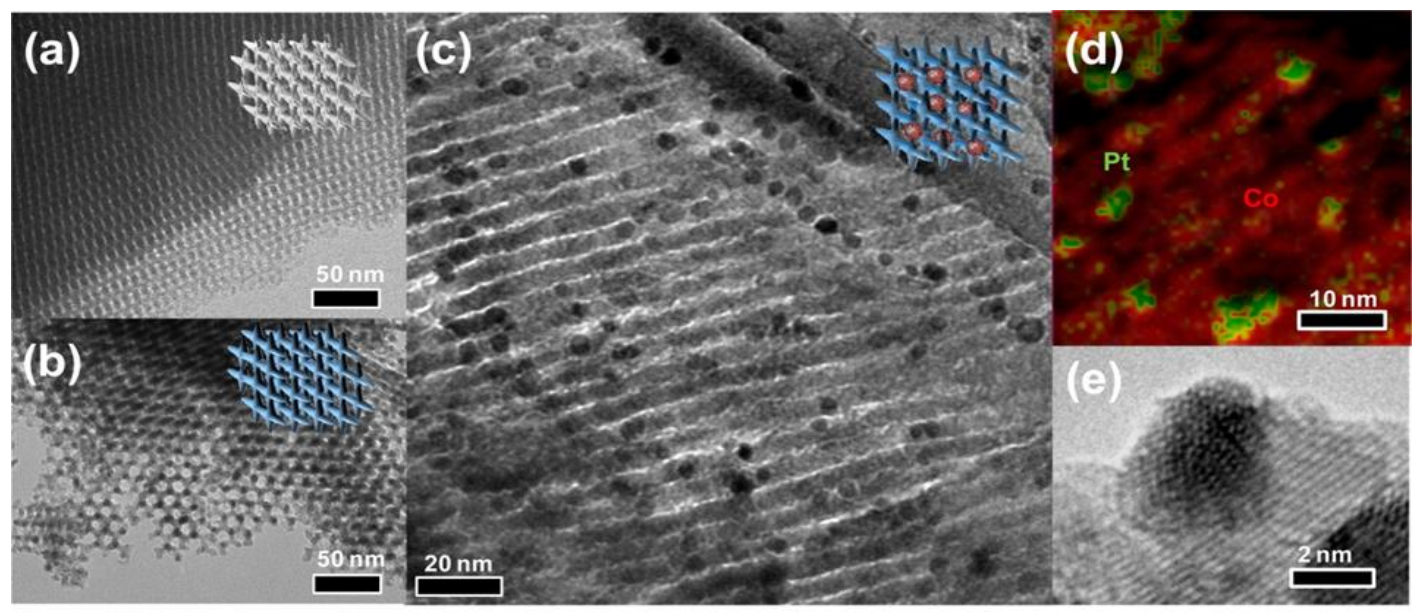

(f)
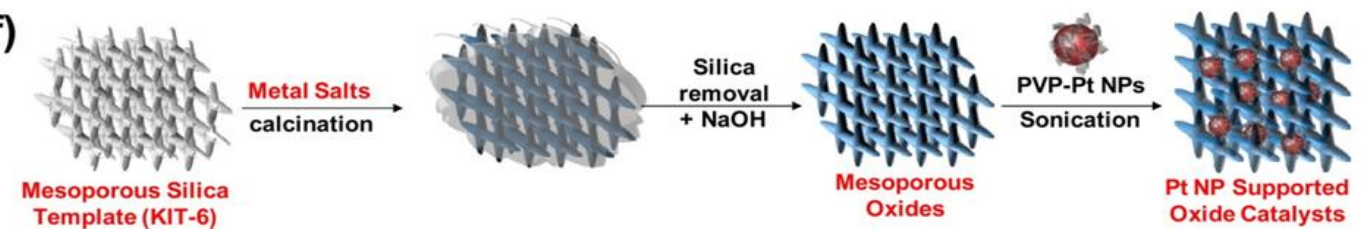

Fig. 5: Preparation of Pt-nanoparticle-loaded $\mathrm{Co}_{3} \mathrm{O}_{4}$ catalysts. TEM images of (a) mesoporous silica template and (b) the resulting $\mathrm{Co}_{3} \mathrm{O}_{4}$ replica. TEM image of (c) $\mathrm{Pt} / \mathrm{Co}_{3} \mathrm{O}_{4}$ catalysts and (d) their corresponding energy-dispersive spectroscopy (EDS) phase mapping, showing the distribution of $\mathrm{Co}$ (red) and $\mathrm{Pt}$ (green) atoms on the surface. (e) High-resolution TEM image of $\mathrm{Pt} / \mathrm{Co}_{3} \mathrm{O}_{4}$ catalysts. (f) Illustration of the hard-templating approach for the preparation of mesoporous-oxide-supported Pt nanoparticle catalysts.

The pure mesoporous oxide supports showed notable catalytic reactivity in the absence of a metal, for example TOF rates of 0.015 and $0.01 \mathrm{sec}^{-1}$ were measured with $\mathrm{Co}_{3} \mathrm{O}_{4}$ and $\mathrm{NiO}$, respectively (under reducing conditions of 100 Torr $\mathrm{CO}, 40$ Torr $\mathrm{O}_{2}$ and $473 \mathrm{~K}$ ). The incorporation of $\mathrm{Pt}$ nanoparticles within the mesoporous oxides increased the catalytic reactivity by more than two orders of magnitudes (Fig. 6).

The measured $\mathrm{CO}$ oxidation rates for $\mathrm{Pt} / \mathrm{Co}_{3} \mathrm{O}_{4}$ and $\mathrm{Pt} / \mathrm{NiO}$ were 500 and $1.1 \mathrm{sec}^{-1}$, respectively. It should be noted that the TOF rate of $\mathrm{SiO}_{2}$ supported $\mathrm{Pt}$ nanoparticles, in which the support is catalytically-inert, was $0.1 \mathrm{sec}^{-1}$. The reactivity of oxide-supported metallic catalysts was significantly higher than the combined reactivity of the metaloxide itself and the Pt nanoparticles. For example, the combined reactivity of silicasupported $\mathrm{Pt}$ nanoparticles and $\mathrm{Co}_{3} \mathrm{O}_{4}$ (without $\mathrm{Pt}$ ) was $0.11 \mathrm{sec}^{-1}$, while the reaction rate of $\mathrm{Pt} / \mathrm{Co}_{3} \mathrm{O}_{4}$ was $500 \mathrm{sec}^{-1}$. These result indicates an enhancement of 3 orders of magnitude in the reaction rate due to the formation of metal/metal-oxide interface. The enhanced reactivity can be explained in the following mechanism: $\mathrm{CO}$ is adsorbed on the 
Pt surface and diffuses to the metal/metal-oxide interface (Fig. 6b, inset). CO will then interact with active oxygen in the lattice of the metal-oxide support. The last step will be the refill of oxygen vacancies in the oxide by gaseous $\mathrm{O}_{2}[15,18]$.

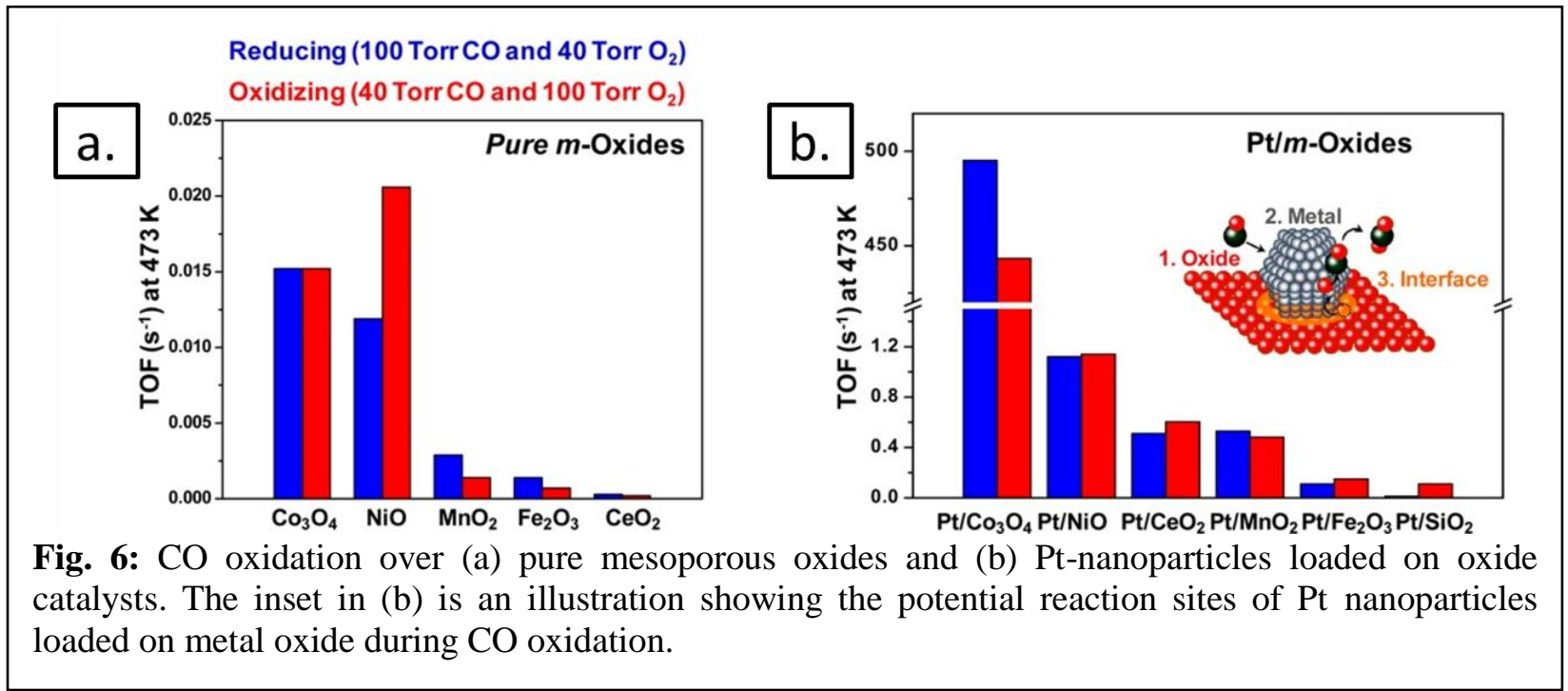

In order to understand the reasons for enhanced reactivity of oxide-supported $\mathrm{Pt}$ nanoparticles, in situ NEXAFS and XPS measurements were conducted under reaction conditions (Fig. 7). The different supported catalysts were exposed to $\mathrm{CO}$ and $\mathrm{O}_{2}$ mixture at $473 \mathrm{~K}$. The NEXAFS total electron yield (TEY) spectra of the metal L edge was monitored by detecting the compensating electrons from ground to sample.

The Co L edge of $\mathrm{Pt} / \mathrm{Co}_{3} \mathrm{O}_{4}$ was monitored under reducing (39 torr $\mathrm{CO}$ and 15 torr $\mathrm{O}_{2}$ ) and oxidizing (15 torr $\mathrm{CO}$ and 39 torr $\mathrm{O}_{2}$ ) conditions at 473 and 523K. NEXAFS measurements revealed that the metal-oxide support is transformed from $\mathrm{Co}_{3} \mathrm{O}_{4}$ into $\mathrm{CoO}$ under reducing conditions at $523 \mathrm{~K}$. It was uncovered that under these conditions the oxidation state of the metal-oxide support is reduced to $\mathrm{CoO}$ at near-surface regions. The lower oxidation state of the support induced stronger interaction with $\mathrm{O}_{2}$ molecules, facilitating their dissociation and enhancing the $\mathrm{CO}_{2}$ formation rate. These results demonstrate the important role of the oxidation state of the metal-oxide during catalytic reaction. 


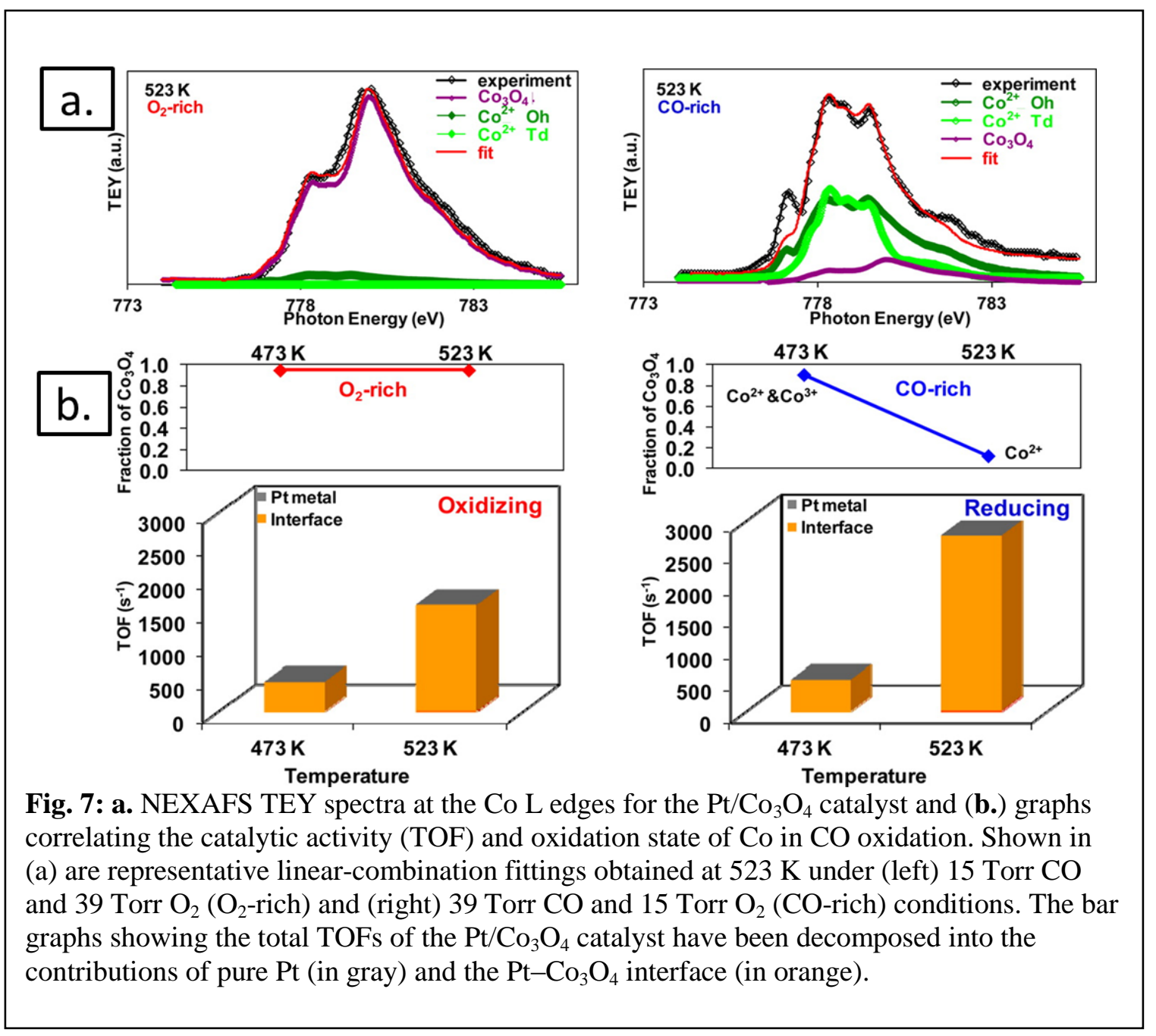

The reaction rate over oxide supported Pt nanoparticles can be enhanced by tuning the redox properties of the metal-oxide. Even after $\mathrm{O}_{2}$-deficicent conditions, active oxygen was provided from the lattice of the oxide to facilitate the catalytic reaction. The redox properties of the metal-oxide support provide the activated oxygen at the metal/metaloxide interface which enhances the catalytic rate. As analyzed by in-situ X-ray measurements, the correlation between surface redox chemistry and catalytic reactivity offers a unique way to tune the catalytic reactivity by controlling the electronic properties of the metal oxide support.

\subsection{Bridging the gap between homogeneous and heterogeneous catalysis with dendrimer-encapsulated Au nanoparticles:}


Continuous efforts in catalysis research have been devoted to activation of heterogeneous catalysts toward reactions that are mainly activated by homogeneous catalysts [62]. Replacing homogeneous catalysts with heterogeneous catalysts enhance the sustainability of the catalytic reaction, providing a highly recyclable, scalable and efficient setup. It was recently reported that small $(<2 \mathrm{~nm})$ metallic nanoclusters, encapsulated in a dendrimer matrix and supported on mesoporous $\mathrm{SiO}_{2}$, show unique reactivity and selectivity toward a wide array of $\pi$-bond activation reactions that are mainly catalyzed by homogeneous catalysts [58, 63-66]. The small size of the nanoparticles enables reversible oxidation of the metal clusters into catalytically active metal ions [66, 67]. Encapsulation of the metal within the dendrimer matrix prevents the leaching of highly oxidized metal ions into the solution phase, inducing high catalytic stability and recyclability of the catalyst. Activation of complex organic reactions with heterogeneous catalysts provides unique opportunities to control and direct the products selectivity. For example, by tuning the packing density of the polymeric matrix that encapsulates the metal cluster and maximizing its steric effect, the products diastereoselectivity can be modified [63, 64]. In addition, as will be further demonstrated in the following paragraphs, the product selectivity in multistep reactions can be tuned by changing the residence time of reactant molecules within a flow reactor $[42,64]$.

Dendrimer-encapsulated $\mathrm{Au}$ nanoparticles with diameter of $2 \mathrm{~nm}$ were loaded on mesoporous $\mathrm{SiO}_{2}$, packed in a flow micro-reactor and utilized as a heterogeneous catalyst for the cascade reaction of dihydropyran synthesis (Fig. 8a). In this reaction, propargyl vinyl ether 1 was catalytically rearranged by the Au catalyst into the primary product, allenic aldehyde $\mathbf{2}$. Activation of the primary product $\mathbf{2}$ by the Au catalyst was followed by nucleophilic attack of butanol- $\mathrm{d}_{10}$ leading to the formation of the secondary product, acetal 3. In order to track the reactants into products transformation within the flow microreactor, this multistep reaction was mapped with a spatial resolution of $15 \mu \mathrm{m}$, employing synchrotron-sourced IR and X-ray beams. High resolution mapping of the catalytic reaction with IR microspectroscopy detected the reactants into products evolution, while X-ray microspectroscopy revealed the oxidation state of the catalyst along the flow reactors (Fig. 8b). 


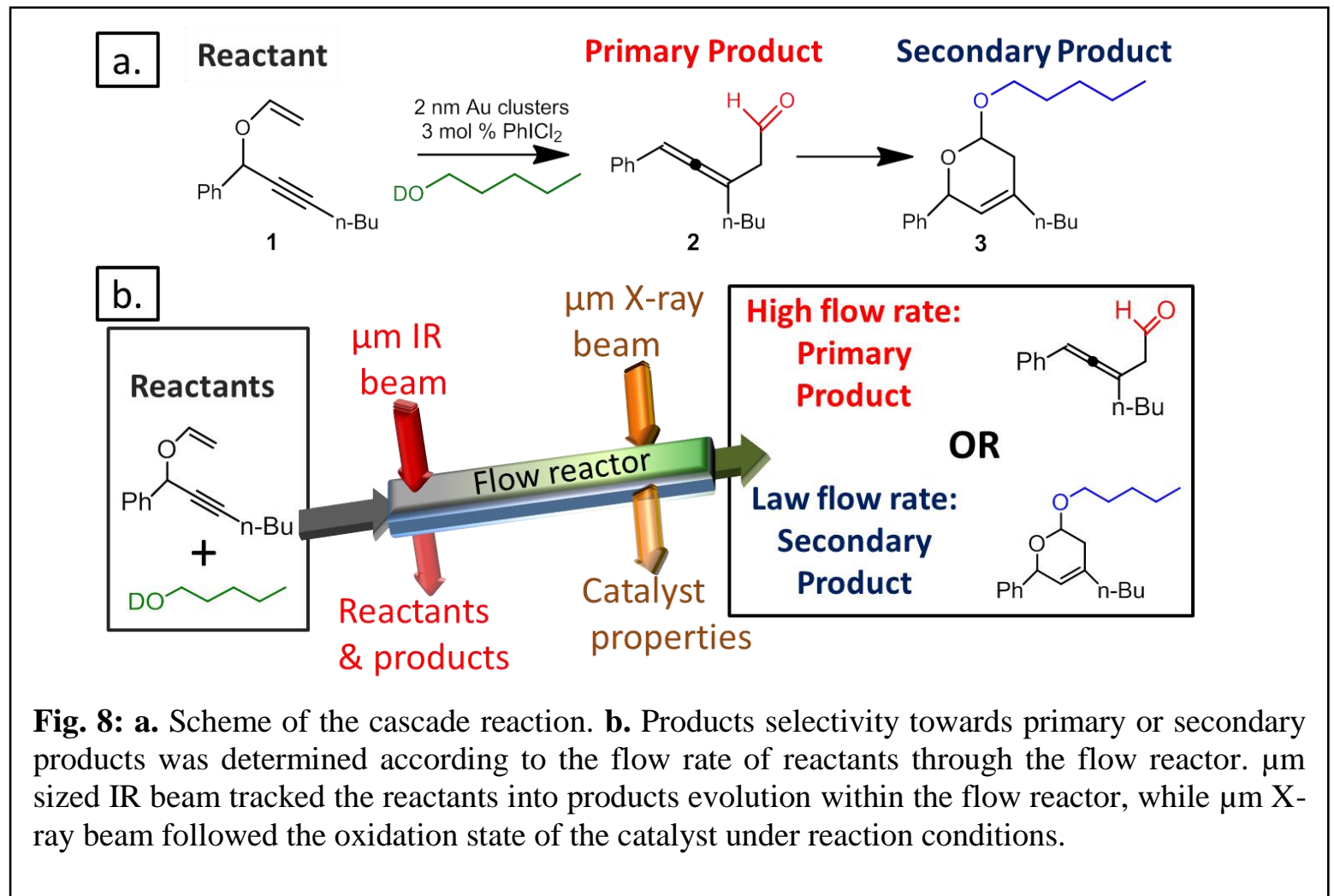

Prior to the catalytic reaction, dendrimer encapsulated Au nanoparticles were oxidized to $\mathrm{Au}$ ions by a flow of an inorganic oxidizer, $\mathrm{PhICl}_{2}$, solvated in toluene. Following the formation of catalytically active, highly oxidized Au ions, the catalyst was tested toward the cascade reaction of dihydropyran formation.

The products selectivity was tuned by modifying the residence time of the reactants. High flow rate of $10 \mathrm{~mL} / \mathrm{h}$ induced low conversion (20\%) and a primary:secondary (2:3) products ratio of 5:1. Higher yield (75\%) was obtained by decreasing the flow rate by 50 fold to $0.2 \mathrm{~mL} / \mathrm{h}$, while the products selectivity (2:3) was transformed to $0: 100$ (Fig. 8 b). These results demonstrate the advantage in performing catalytic transformations in flow microreactors, enabling isolation of either the primary or secondary products [42, 60, 64]. Tunable selectivity between different products in cascade reactions is not easily achieved while employing homogeneous or heterogeneous catalysts in a batch reactor. Though isolation of the secondary product is possible in batch mode reactions, the exclusive formation of primary product is not a simple task. 
In the cascade dihydropyran formation reaction each of the reactants and products show distinguishable IR signatures (Fig. 9a-b). As a consequence, the transformation of reactants into products can be visualized with IR microspectroscopy. The IR measurements were performed along the flow reactor with continuous reactants flow, ensuring that the reactants and products concentrations at each point along the flow reactor were at steady state (Fig. 9c).

With a flow rate to $1 \mathrm{~mL} / \mathrm{h}$ (Figure 9a), a decrease in the reactant, vinyl ether $\mathbf{1}$, absorption peaks amplitude (around 1150-1250 $\mathrm{cm}^{-1}$ ) was indicated and followed by the formation of a strong absorption peak of the primary product, aldehyde 2. After $0.2 \mathrm{~mm}$, a gradual decrease in the aldehyde absorption peak along with a comparable decrease in the higher energy (between 2300 and $2700 \mathrm{~cm}^{-1}$ ) absorption spectra regime indicated the parallel consumption of butanol- $d_{10}$ and aldehyde 2 to the formation of the secondary product, acetal $\mathbf{3}$.

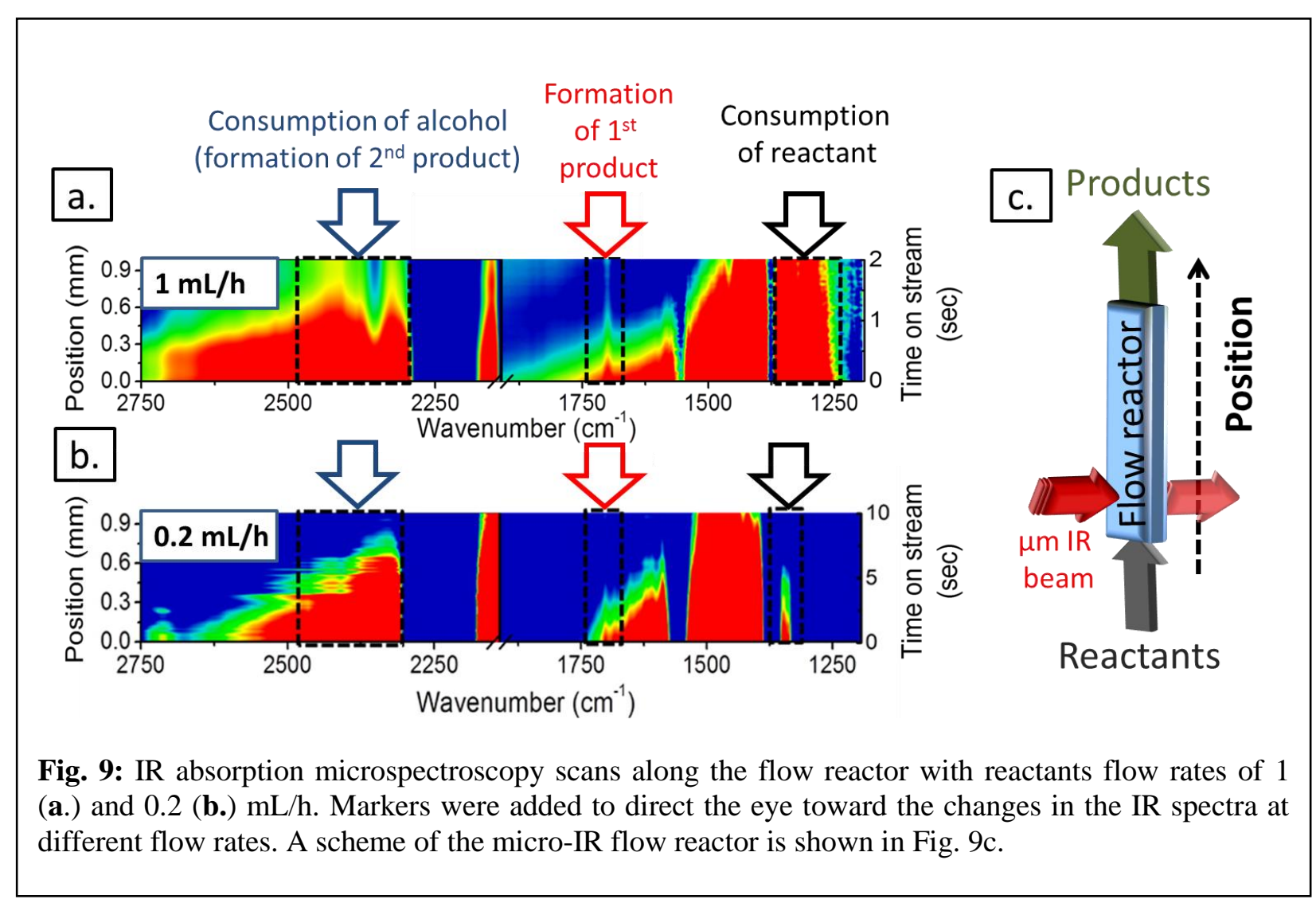

Higher reaction rates were obtained when increasing the residence time of the reactants by 5 -fold (Figure 9b), as obtained by the complete loss of the reactant's absorption peaks 
at $1150-1250 \mathrm{~cm}^{-1}$ after $0.6 \mathrm{~mm}$. Though primary product, 2 , was initially formed, after $0.4 \mathrm{~mm}$ the aldehyde IR signature was fully lost. This result indicates the catalytic transformation from primary into secondary product. The formation of secondary product, acetal $\mathbf{3}$, is demonstrated as well by the total consumption of butanol- $d_{10}$, as observed by the gradual decrease of the O-D absorption peak at $2300-2650 \mathrm{~cm}^{-1}$ until its disappearance after $0.8 \mathrm{~mm}$. At this flow rate, consumption of the reactant was followed by formation of the primary product, which then further transforms into the secondary product.

Subsequent to the FTIR microspectroscopy measurements the reactants and products were also analyzed by GC. All the conclusions, both regarding the catalytic reactivity and products selectivity, which were derived from the IR measurements, were supported by the GC analysis. The synchrotron-based IR microreactor and the lab-based stainless-steel microreactor were designed to have similar inner volume, ensuring comparable residence time of the reactants. GC analysis verified that the yield and selectivity of the products in these two microreactors were comparable, with variations of up to $\pm 15 \%$.

A detailed kinetic analysis of the catalytic reaction was performed by integrating the IR absorption peaks of the reactants and products along the flow reactor (Fig. 10). The evolution of the reaction at flow rate of $1 \mathrm{~mL} / \mathrm{h}$ can be divided into two parts (Fig. 10a). In the first part of the reaction $(0-0.3 \mathrm{~mm})$ vinyl ether 1 was consumed for the formation of allenic aldehyde 2 . During the second part of the reaction, the secondary product was formed and a linear decrease (zero order kinetics) in the concentration of the two reactants was measured. 

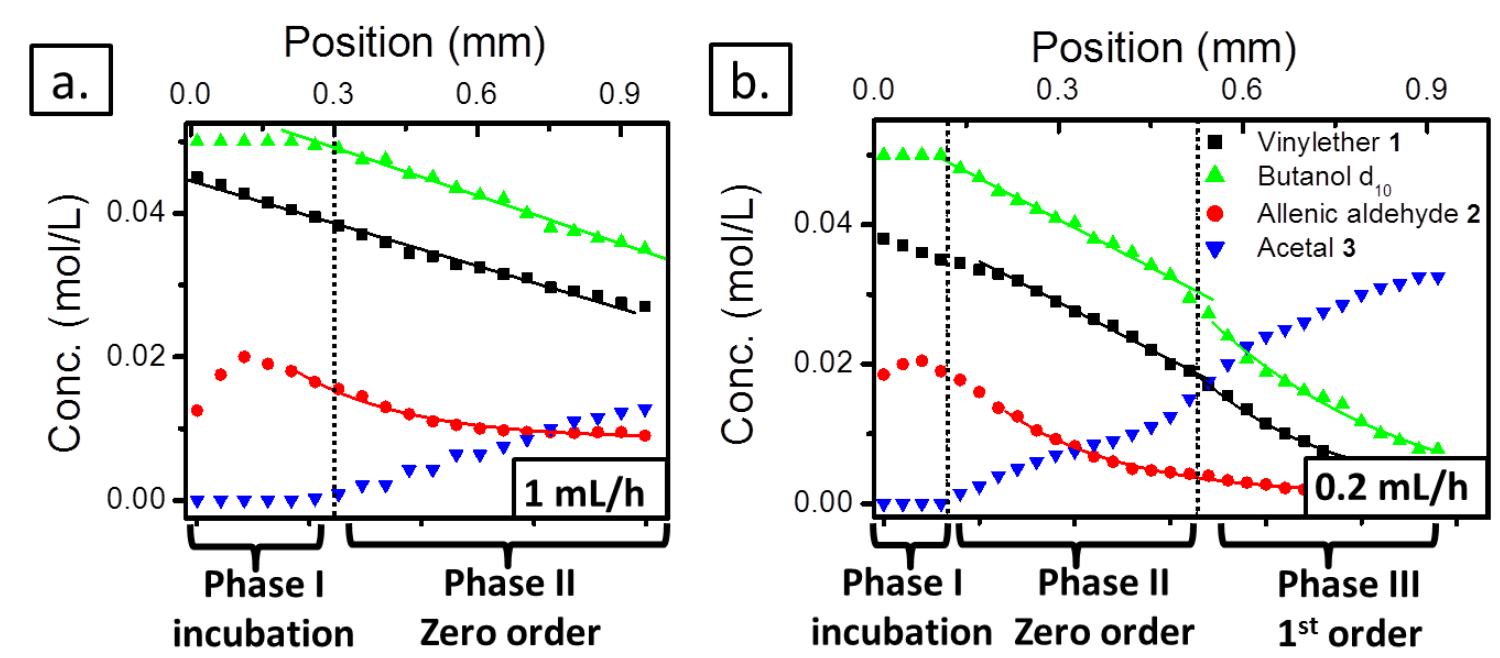

Fig. 10: Analysis of distribution of reactants and products as a function of location along the flow reactor at a flow rate of 1 (a.) and 0.2 (b.) $\mathrm{mL} / \mathrm{h}$. The absorption values of the reactants and products were integrated from the matching IR absorption peak areas and converted to concentration based on GC analysis of the solution. The dotted lines indicate the different stages of the catalytic reaction.

The kinetic evolution of the reaction at slower flow rate of $0.2 \mathrm{~mL} / \mathrm{h}$ was divided into three phases (Fig. 10b). During the initial phase of the reaction $(0-0.14 \mathrm{~mm})$ the concentration of reactant $\mathbf{1}$ gradually decreased due to formation of primary product $\mathbf{2}$. Within this incubation time, no formation of secondary product $\mathbf{3}$ or consumption of butanol- $\mathrm{d}_{10}$ were detected. Through the second part of the reaction $(0.14-0.52 \mathrm{~mm})$, the two reactants (vinyl ether $\mathbf{1}$ and butanol- $\mathrm{d}_{10}$ ) and the primary product (allenic aldehyde $\mathbf{2}$ ) were consumed along with formation of the secondary product, acetal 3 . At this stage of the reaction, the local concentrations of the two reactants (vinyl ether $\mathbf{1}$ and butanol- $\mathrm{d}_{10}$ ) saturate the catalyst, inducing zero order kinetics. The similarities in the consumption rate of the two reactants are consistent with the fast transformation of primary product $\mathbf{2}$ into secondary product $\mathbf{3}$, indicating that the rate determining step is the conversion of reactant 1 into primary product 2 . At the third phase of the reaction $(0.52-1 \mathrm{~mm})$ the concentration of the reactants was low enough to change the reaction kinetics from zero to first order for the two reactants. At this step, a continuous low, steady state concentration of allenic aldehyde $\mathbf{2}$ was detected, demonstrating its essential role as an intermediate for the formation of the secondary product, acetal 3. 
NEXAFS microspectroscopy measurements along the flow reactor revealed that after 2 $\mathrm{mm}$ the concentration of the catalytically active $\mathrm{Au}(\mathrm{III})$ species was gradually decreasing due to $\mathrm{Au}(\mathrm{III})$ reduction into $\mathrm{Au}(0)$. The reduction process was correlated to the nucleophilic properties of butanol- $\mathrm{d}_{10}$, which reduce the $\mathrm{Au}$ (III) back to its metallic state. Based upon the IR and X-ray measurements, the catalytic system was further optimized to enhance the reactivity and decrease the deactivation rate of the catalyst. The reactants concentration was decreased in order to lower the reduction rate of $\mathrm{Au}(\mathrm{III})$ by butanol$\mathrm{d}_{10}$. NEXAFS results indicated that only the initial part of the reactor was active during the catalytic process. According to this observation, the total amount of Au catalyst was reduced by an order of magnitude and the length of the microreactor was decreased from $2 \mathrm{~cm}$ to $2 \mathrm{~mm}$. Though the amount of the catalyst was reduced by an order of magnitude, only negligible decrease was obtained in the catalytic reactivity. These results indicate the importance of in-situ spectroscopy of the catalytic reaction for analysis and optimization of the catalytic process.

\section{Conclusions}

The combination of (i) synthesis of catalytic nanostructures (ii) testing their catalytic properties and (iii) in-situ spectroscopic analysis provides powerful capabilities to investigate and optimize catalytic processes. In this review paper, three recent examples from our research group demonstrated the advantages of this approach.

In the first example it was shown that the mechanism for size-dependent catalytic selectivity can be revealed by in-situ SFG vibrational spectroscopy. Gas-phase hydrogenation of 1,3-butadiene by size selected Pt nanoparticles induce the production of either fully or partially saturated products. SFG analysis indicated the formation of different intermediates in accordance to the Pt clusters size, revealing the mechanism for size dependent products selectivity. In the second example, synchrotron based X-ray spectroscopy tracked the oxidation state of catalysts under reaction conditions. It was demonstrated that $\mathrm{CO}$ oxidation rate can be dramatically enhanced by loading catalytically active Pt nanoparticles on mesoporous metal-oxides. NEXAFS and HP-XPS spectroscopy analyzed the oxidation state of the metal-oxide surface under reaction conditions, correlating between oxidation state and the catalytic rate. 
The combination of spectroscopy and microscopy measurements for high spatial resolution analysis of catalytic reactions was demonstrated in the third example. By combining X-ray and IR microspectroscopy analysis, the reactants to products evolution and the electronic properties of the catalyst within a flow reactor were detected. In-situ synchrotron-sourced IR microspectroscopy detected the evolution of reactant into primary and then into secondary product. By tuning the residence time of the reactants in a flow microreactor, a detailed kinetic analysis of the reaction was performed. The utilization of different spectroscopic tools under reaction conditions gives access to invaluable data regarding the properties that govern the catalytic reaction. As demonstrated throughout this review paper, spectroscopic analysis can be utilized for preparation of better catalysts, with optimized stability, reactivity and selectivity.

Looking ahead, the field of in-situ spectroscopy of catalytic reactions can be further developed in two parallel routs:

(I) Combining few spectroscopic tools that simultaneously analyze the catalytic reaction and enable a comprehensive analysis of catalytic processes [35, 68, 69]. For example, the hydrothermal crystallization process of zeolites from amorphous precursor gel into a crystalline microporous material was detected with combined in situ X-ray and Raman spectroscopy [70]. This study revealed fundamental insights regarding the construction of catalytic nanostructures, correlating between the vibrational spectrum, as revealed by Raman spectroscopy and the structural and electronic properties, as detected by X-ray spectroscopy.

(II) Increasing the spatial resolution of microspectroscopy measurements into the nanoscale size regime [71-73]. A variety of studies indicated the capabilities of IR and Xray spectroscopy at the nanoscale. In a recent example, X-ray measurements were conducted to visualize the microstructural evolution of lithium-ion batteries [47] and catalysts [74] under reaction conditions. In-situ 3D quantitative analysis of structural changes at the nanoscale offers a direct way to understand the mechanical changes of catalytic nanostructures under reaction conditions. Another promising approach utilizes tip enhanced IR and Raman spectroscopy as a route to further enhance the spatial resolution of microspectroscopy measurements into the nanoscale [75-77]. These novel 
spectroscopic methods are expected to open up new levels of fundamental understanding of catalytic processes which cannot be otherwise accessed.

\section{Acknowledgements}

This work was supported by the Director, Office of Basic Energy Sciences, Materials Science and Engineering Division and the Division of Chemical Sciences, Geological and Biosciences of the U.S. Department of Energy under Contract No. DE-AC0205CH11231. Work at the Molecular Foundry was supported by the Director, Office of Science, Office of Basic Energy Sciences, Division of Material Sciences and Engineering, of the U.S. Department of Energy under Contract No. DE-AC0205CH11231. The X-ray absorption spectroscopy and IR microspectroscopy studies were performed at the Advanced Light Source, a DOE User facility of the Office of Science, Office of Basic Energy Sciences.

\section{References}

[1] K. An, G.A. Somorjai, Size and Shape Control of Metal Nanoparticles for Reaction Selectivity in Catalysis, Chemcatchem, 4 (2012) 1512-1524.

[2] K. Na, Q. Zhang, G.A. Somorjai, Colloidal Metal Nanocatalysts: Synthesis, Characterization, and Catalytic Applications, J Clust Sci, 25 (2014) 83-114.

[3] H. Zhang, M.S. Jin, Y.J. Xiong, B. Lim, Y.N. Xia, Shape-Controlled Synthesis of Pd Nanocrystals and Their Catalytic Applications, Accounts Chem Res, 46 (2013) 1783-1794.

[4] B.R. Cuenya, Synthesis and catalytic properties of metal nanoparticles: Size, shape, support, composition, and oxidation state effects, Thin Solid Films, 518 (2010) 3127-3150.

[5] M.S. Chen, D.W. Goodman, Structure-activity relationships in supported Au catalysts, Catal Today, 111 (2006) 22-33.

[6] S. Bordiga, E. Groppo, G. Agostini, J.A. van Bokhoven, C. Lamberti, Reactivity of Surface Species in Heterogeneous Catalysts Probed by In Situ X-ray Absorption Techniques, Chem Rev, 113 (2013) 1736-1850.

[7] E. Gross, J.M. Krier, L. Heinke, G.A. Somorjai, Building Bridges in Catalysis Science. Monodispersed Metallic Nanoparticles for Homogeneous Catalysis and Atomic Scale Characterization of Catalysts Under Reaction Conditions, Top Catal, 55 (2012) 13-23.

[8] C. Lamberti, A. Zecchina, E. Groppo, S. Bordiga, Probing the surfaces of heterogeneous catalysts by in situ IR spectroscopy, Chem Soc Rev, 39 (2010) 4951-5001.

[9] B.M. Weckhuysen, Chemical Imaging of Spatial Heterogeneities in Catalytic Solids at Different Length and Time Scales, Angew Chem Int Edit, 48 (2009) 4910-4943.

[10] F. Zaera, Probing Liquid/Solid Interfaces at the Molecular Level, Chem Rev, 112 (2012) 29202986.

[11] B.M. Weckhuysen, Snapshots of a working catalyst: possibilities and limitations of in situ spectroscopy in the field of heterogeneous catalysis, Chem Commun, (2002) 97-110. 
[12] C.W. Jones, F. Tao, M.V. Garland, Introduction to Special Issue on Operando and In Situ Studies of Catalysis, Acs Catal, 2 (2012) 2444-2445.

[13] M.S. Chen, D.W. Goodman, Catalytically active gold: From nanoparticles to ultrathin films, Accounts Chem Res, 39 (2006) 739-746.

[14] H.J. Freund, Model Studies in Heterogeneous Catalysis, Chem-Eur J, 16 (2010) 9384-9397.

[15] U. Landman, B. Yoon, C. Zhang, U. Heiz, M. Arenz, Factors in gold nanocatalysis: oxidation of CO in the non-scalable size regime, Top Catal, 44 (2007) 145-158.

[16] M.S. Chen, D.W. Goodman, The structure of catalytically active gold on titania, Science, 306 (2004) 252-255.

[17] M. Valden, X. Lai, D.W. Goodman, Onset of catalytic activity of gold clusters on titania with the appearance of nonmetallic properties, Science, 281 (1998) 1647-1650.

[18] B. Yoon, H. Hakkinen, U. Landman, A.S. Worz, J.M. Antonietti, S. Abbet, K. Judai, U. Heiz, Charging effects on bonding and catalyzed oxidation of $\mathrm{CO}$ on $\mathrm{Au}-8$ clusters on $\mathrm{MgO}$, Science, 307 (2005) 403-407.

[19] A. Boffa, C. Lin, A.T. Bell, G.A. Somorjai, Promotion of Co and Co2 Hydrogenation over Rh by Metal-Oxides - the Influence of Oxide Lewis Acidity and Reducibility, J Catal, 149 (1994) 149-158. [20] A.B. Boffa, C. Lin, A.T. Bell, G.A. Somorjai, Lewis Acidity as an Explanation for Oxide Promotion of Metals - Implications of Its Importance and Limits for Catalytic Reactions, Catal Lett, 27 (1994) 243-249.

[21] I.X. Green, W.J. Tang, M. Neurock, J.T. Yates, Spectroscopic Observation of Dual Catalytic Sites During Oxidation of CO on a Au/TiO2 Catalyst, Science, 333 (2011) 736-739.

[22] E. Gross, M. Asscher, M. Lundwall, D.W. Goodman, Gold nanoclusters deposited on SiO2 via water as buffer layer: CO-IRAS and TPD characterization, J Phys Chem C, 111 (2007) 1619716201.

[23] M.C. Kung, R.J. Davis, H.H. Kung, Understanding Au-catalyzed low-temperature CO oxidation, J Phys Chem C, 111 (2007) 11767-11775.

[24] H.J. Freund, Metal-supported ultrathin oxide film systems as designable catalysts and catalyst supports, Surf Sci, 601 (2007) 1438-1442.

[25] C. Burda, X.B. Chen, R. Narayanan, M.A. El-Sayed, Chemistry and properties of nanocrystals of different shapes, Chem Rev, 105 (2005) 1025-1102.

[26] C.K. Tsung, J.N. Kuhn, W.Y. Huang, C. Aliaga, L.I. Hung, G.A. Somorjai, P.D. Yang, Sub-10 nm Platinum Nanocrystals with Size and Shape Control: Catalytic Study for Ethylene and Pyrrole Hydrogenation, J Am Chem Soc, 131 (2009) 5816-5822.

[27] S. Carrettin, P. Concepcion, A. Corma, J.M.L. Nieto, V.F. Puntes, Nanocrystalline CeO2 increases the activity of an for $\mathrm{CO}$ oxidation by two orders of magnitude, Angew Chem Int Edit, 43 (2004) 2538-2540.

[28] P. Sonstrom, M. Baumer, Supported colloidal nanoparticles in heterogeneous gas phase catalysis: on the way to tailored catalysts, Phys Chem Chem Phys, 13 (2011) 19270-19284.

[29] C. Aliaga, J.Y. Park, Y. Yamada, H.S. Lee, C.K. Tsung, P.D. Yang, G.A. Somorjai, Sum Frequency Generation and Catalytic Reaction Studies of the Removal of Organic Capping Agents from Pt Nanoparticles by UV-Ozone Treatment, J Phys Chem C, 113 (2009) 6150-6155.

[30] J.M. Krier, W.D. Michalak, L.R. Baker, K. An, K. Komvopoulos, G.A. Somorjai, Sum Frequency Generation Vibrational Spectroscopy of Colloidal Platinum Nanoparticle Catalysts: Disordering versus Removal of Organic Capping, J Phys Chem C, 116 (2012) 17540-17546.

[31] J.A. Lopez-Sanchez, N. Dimitratos, C. Hammond, G.L. Brett, L. Kesavan, S. White, P. Miedziak, R. Tiruvalam, R.L. Jenkins, A.F. Carley, D. Knight, C.J. Kiely, G.J. Hutchings, Facile removal of stabilizer-ligands from supported gold nanoparticles, Nat Chem, 3 (2011) 551-556. 
[32] L.R. Baker, G. Kennedy, M. Van Spronsen, A. Hervier, X.J. Cai, S.Y. Chen, L.W. Wang, G.A. Somorjai, Furfuraldehyde Hydrogenation on Titanium Oxide-Supported Platinum Nanoparticles Studied by Sum Frequency Generation Vibrational Spectroscopy: Acid-Base Catalysis Explains the Molecular Origin of Strong Metal-Support Interactions, J Am Chem Soc, 134 (2012) 1420814216.

[33] F. Tao, S. Dag, L.W. Wang, Z. Liu, D.R. Butcher, H. Bluhm, M. Salmeron, G.A. Somorjai, Break-Up of Stepped Platinum Catalyst Surfaces by High CO Coverage, Science, 327 (2010) 850853.

[34] F. Tao, M.E. Grass, Y.W. Zhang, D.R. Butcher, J.R. Renzas, Z. Liu, J.Y. Chung, B.S. Mun, M. Salmeron, G.A. Somorjai, Reaction-Driven Restructuring of Rh-Pd and Pt-Pd Core-Shell Nanoparticles, Science, 322 (2008) 932-934.

[35] M.A. Newton, W. van Beek, Combining synchrotron-based X-ray techniques with vibrational spectroscopies for the in situ study of heterogeneous catalysts: a view from a bridge, Chem Soc Rev, 39 (2010) 4845-4863.

[36] E. Stavitski, B.M. Weckhuysen, Infrared and Raman imaging of heterogeneous catalysts, Chem Soc Rev, 39 (2010) 4615-4625.

[37] G. Kennedy, L.R. Baker, G.A. Somorjai, Selective Amplification of C $=0$ Bond Hydrogenation on Pt/TiO2: Catalytic Reaction and Sum- Frequency Generation Vibrational Spectroscopy Studies of Crotonaldehyde Hydrogenation, Angew Chem Int Edit, 53 (2014) 3405-3408.

[38] F. Gao, Y.L. Wang, D.W. Goodman, Reaction Kinetics and Polarization-Modulation Infrared Reflection Absorption Spectroscopy (PM-IRAS) Investigation of CO Oxidation over Supported PdAu Alloy Catalysts, J Phys Chem C, 114 (2010) 4036-4043.

[39] C. Rameshan, C. Weilach, W. Stadlmayr, S. Penner, H. Lorenz, M. Havecker, R. Blume, T. Rocha, D. Teschner, A. Knop-Gericke, R. Schlogl, D. Zemlyanov, N. Memmel, G. Rupprechter, B. Klotzer, Steam reforming of methanol on $\mathrm{PdZn}$ near-surface alloys on $\mathrm{Pd}(111)$ and $\mathrm{Pd}$ foil studied by in-situ XPS, LEIS and PM-IRAS, J Catal, 276 (2010) 101-113.

[40] X.Z. Shu, M. Zhang, Y. He, H. Frei, F.D. Toste, Dual Visible Light Photoredox and GoldCatalyzed Arylative Ring Expansion, J Am Chem Soc, 136 (2014) 5844-5847.

[41] M. Zhang, M. de Respinis, H. Frei, Time-resolved observations of water oxidation intermediates on a cobalt oxide nanoparticle catalyst, Nat Chem, 6 (2014) 362-367.

[42] E. Gross, X.Z. Shu, S. Alayoglu, H.A. Bechtel, M.C. Martin, F.D. Toste, G.A. Somorjai, In Situ IR and X-ray High Spatial-Resolution Microspectroscopy Measurements of Multistep Organic Transformation in Flow Microreactor Catalyzed by Au Nanoclusters, J Am Chem Soc, 136 (2014) 3624-3629.

[43] E. Stavitski, M.H.F. Kox, I. Swart, F.M.F. de Groot, B.M. Weckhuysen, In situ synchrotronbased IR microspectroscopy to study catalytic reactions in zeolite crystals, Angew Chem Int Edit, 47 (2008) 3543-3547.

[44] A. Urakawa, N. Maeda, A. Baiker, Space- and Time-Resolved Combined DRIFT and Raman Spectroscopy: Monitoring Dynamic Surface and Bulk Processes during NO(x) Storage Reduction, Angew Chem Int Edit, 47 (2008) 9256-9259.

[45] A.M. Beale, B.M. Weckhuysen, EXAFS as a tool to interrogate the size and shape of mono and bimetallic catalyst nanoparticles, Phys Chem Chem Phys, 12 (2010) 5562-5574.

[46] A.I. Frenkel, J.A. Rodriguez, J.G.G. Chen, Synchrotron Techniques for In Situ Catalytic Studies: Capabilities, Challenges, and Opportunities, Acs Catal, 2 (2012) 2269-2280.

[47] M. Ebner, F. Marone, M. Stampanoni, V. Wood, Visualization and Quantification of Electrochemical and Mechanical Degradation in Li Ion Batteries, Science, 342 (2013) 716-720.

[48] E.K. Gibson, M.W. Zandbergen, S.D.M. Jacques, C. Biao, R.J. Cernik, M.G. O'Brien, M. Di Michiel, B.M. Weckhuysen, A.M. Beale, Noninvasive Spatiotemporal Profiling of the Processes of 
Impregnation and Drying within Mo/Al2O3 Catalyst Bodies by a Combination of X-ray Absorption Tomography and Diagonal Offset Raman Spectroscopy, Acs Catal, 3 (2013) 339-347. [49] J. Ruiz-Martinez, A.M. Beale, U. Deka, M.G. O'Brien, P.D. Quinn, J.F.W. Mosselmans, B.M. Weckhuysen, Correlating Metal Poisoning with Zeolite Deactivation in an Individual Catalyst Particle by Chemical and Phase-Sensitive X-ray Microscopy, Angew Chem Int Edit, 52 (2013) 5983-5987.

[50] I.D. Gonzalez-Jimenez, K. Cats, T. Davidian, M. Ruitenbeek, F. Meirer, Y.J. Liu, J. Nelson, J.C. Andrews, P. Pianetta, F.M.F. de Groot, B.M. Weckhuysen, Hard X-ray Nanotomography of Catalytic Solids at Work, Angew Chem Int Edit, 51 (2012) 11986-11990.

[51] W.D. Michalak, J.M. Krier, K. Komvopoulos, G.A. Somorjai, Structure Sensitivity in Pt Nanoparticle Catalysts for Hydrogenation of 1,3-Butadiene: In Situ Study of Reaction Intermediates Using SFG Vibrational Spectroscopy, J Phys Chem C, 117 (2013) 1809-1817.

[52] K. An, S. Alayoglu, N. Musselwhite, S. Plamthottam, G. Melaet, A.E. Lindeman, G.A. Somorjai, Enhanced CO Oxidation Rates at the Interface of Mesoporous Oxides and Pt Nanoparticles, J Am Chem Soc, 135 (2013) 16689-16696.

[53] G. Melaet, A.E. Lindeman, G.A. Somorjai, Cobalt Particle Size Effects in the Fischer-Tropsch Synthesis and in the Hydrogenation of $\mathrm{CO} 2$ Studied with Nanoparticle Model Catalysts on Silica, Top Catal, 57 (2014) 500-507.

[54] V.V. Pushkarev, K.J. An, S. Alayoglu, S.K. Beaumont, G.A. Somorjai, Hydrogenation of benzene and toluene over size controlled Pt/SBA-15 catalysts: Elucidation of the Pt particle size effect on reaction kinetics, J Catal, 292 (2012) 64-72.

[55] J.K. Norskov, T. Bligaard, B. Hvolbaek, F. Abild-Pedersen, I. Chorkendorff, C.H. Christensen, The nature of the active site in heterogeneous metal catalysis, Chem Soc Rev, 37 (2008) 2163 2171.

[56] L. Li, A.H. Larsen, N.A. Romero, V.A. Morozov, C. Glinsvad, F. Abild-Pedersen, J. Greeley, K.W. Jacobsen, J.K. Norskov, Investigation of Catalytic Finite-Size-Effects of Platinum Metal Clusters, J Phys Chem Lett, 4 (2013) 222-226.

[57] C.J. Kliewer, C. Aliaga, M. Bieri, W.Y. Huang, C.K. Tsung, J.B. Wood, K. Komvopoulos, G.A. Somorjai, Furan Hydrogenation over $\mathrm{Pt}(111)$ and $\mathrm{Pt}(100)$ Single-Crystal Surfaces and Pt Nanoparticles from 1 to $7 \mathrm{~nm}$ : A Kinetic and Sum Frequency Generation Vibrational Spectroscopy Study, J Am Chem Soc, 132 (2010) 13088-13095.

[58] C.A. Witham, W.Y. Huang, C.K. Tsung, J.N. Kuhn, G.A. Somorjai, F.D. Toste, Converting homogeneous to heterogeneous in electrophilic catalysis using monodisperse metal nanoparticles, Nat Chem, 2 (2010) 36-41.

[59] C.H. Yoon, M.X. Yang, G.A. Somorjai, Hydrogenation of 1,3-butadiene on platinum surfaces of different structures, Catal Lett, 46 (1997) 37-41.

[60] E. Gross, G.A. Somorjai, The Impact of Electronic Charge on Catalytic Reactivity and Selectivity of Metal-Oxide Supported Metallic Nanoparticles, Top Catal, 56 (2013) 1049-1058.

[61] A. Taguchi, F. Schuth, Ordered mesoporous materials in catalysis, Micropor Mesopor Mat, 77 (2005) 1-45.

[62] D. Astruc, F. Lu, J.R. Aranzaes, Nanoparticles as recyclable catalysts: The frontier between homogeneous and heterogeneous catalysis, Angew Chem Int Edit, 44 (2005) 7852-7872.

[63] E. Gross, J.H. Liu, S. Alayoglu, M.A. Marcus, S.C. Fakra, F.D. Toste, G.A. Somorjai, Asymmetric Catalysis at the Mesoscale: Gold Nanoclusters Embedded in Chiral Self-Assembled Monolayer as Heterogeneous Catalyst for Asymmetric Reactions, J Am Chem Soc, 135 (2013) 3881-3886. 
[64] E. Gross, J.H.C. Liu, F.D. Toste, G.A. Somorjai, Control of selectivity in heterogeneous catalysis by tuning nanoparticle properties and reactor residence time, Nat Chem, 4 (2012) 947952.

[65] W.Y. Huang, J.H.C. Liu, P. Alayoglu, Y.M. Li, C.A. Witham, C.K. Tsung, F.D. Toste, G.A. Somorjai, Highly Active Heterogeneous Palladium Nanoparticle Catalysts for Homogeneous Electrophilic Reactions in Solution and the Utilization of a Continuous Flow Reactor, J Am Chem Soc, 132 (2010) 16771-16773.

[66] Y.M. Li, J.H.C. Liu, C.A. Witham, W.Y. Huang, M.A. Marcus, S.C. Fakra, P. Alayoglu, Z.W. Zhu, C.M. Thompson, A. Arjun, K. Lee, E. Gross, F.D. Toste, G.A. Somorjai, A Pt-Cluster-Based Heterogeneous Catalyst for Homogeneous Catalytic Reactions: X-ray Absorption Spectroscopy and Reaction Kinetic Studies of Their Activity and Stability against Leaching, J Am Chem Soc, 133 (2011) 13527-13533.

[67] W. Huang, J.N. Kuhn, C.K. Tsung, Y. Zhang, S.E. Habas, P. Yang, G.A. Somorjai, Dendrimer templated synthesis of one nanometer Rh and Pt particles supported on mesoporous silica: Catalytic activity for ethylene and pyrrole hydrogenation, Nano Lett, 8 (2008) 2027-2034.

[68] A. Iglesias-Juez, A.M. Beale, K. Maaijen, T.C. Weng, P. Glatzel, B.M. Weckhuysen, A combined in situ time-resolved UV-Vis, Raman and high-energy resolution X-ray absorption spectroscopy study on the deactivation behavior of $\mathrm{Pt}$ and $\mathrm{Pt}-\mathrm{Sn}$ propane dehydrogenation catalysts under industrial reaction conditions, J Catal, 276 (2010) 268-279.

[69] A. Patlolla, P. Baumann, W. Xu, S.D. Senanayake, J.A. Rodriguez, A.I. Frenkel, Characterization of Metal-Oxide Catalysts in Operando Conditions by Combining X-ray Absorption and Raman Spectroscopies in the Same Experiment, Top Catal, 56 (2013) 896-904.

[70] A.M. Beale, M.G. O'Brien, M. Kasunic, A. Golobic, M. Sanchez-Sanchez, A.J.W. Lobo, D.W. Lewis, D.S. Wragg, S. Nikitenko, W. Bras, B.M. Weckhuysen, Probing ZnAPO-34 Self-Assembly Using Simultaneous Multiple in Situ Techniques, J Phys Chem C, 115 (2011) 6331-6340.

[71] F.M.F. de Groot, E. de Smit, M.M. van Schooneveld, L.R. Aramburo, B.M. Weckhuysen, Insitu Scanning Transmission X-Ray Microscopy of Catalytic Solids and Related Nanomaterials, Chemphyschem, 11 (2010) 951-962.

[72] J.R. Jinschek, Advances in the environmental transmission electron microscope (ETEM) for nanoscale in situ studies of gas-solid interactions, Chem Commun, 50 (2014) 2696-2706.

[73] I.L.C. Buurmans, B.M. Weckhuysen, Heterogeneities of individual catalyst particles in space and time as monitored by spectroscopy, Nature Chem, 4 (2012) 873-886.

[74] K.H. Cats, I.D. Gonzalez-Jimenez, Y.J. Liu, J. Nelson, D. van Campen, F. Meirer, A.M.J. van der Eerden, F.M.F. de Groot, J.C. Andrews, B.M. Weckhuysen, X-ray nanoscopy of cobalt FischerTropsch catalysts at work, Chem Commun, 49 (2013) 4622-4624.

[75] H.A. Bechtel, E.A. Muller, R.L. Olmon, M.C. Martin, M.B. Raschke, Ultrabroadband infrared nanospectroscopic imaging, P Natl Acad Sci USA, 111 (2014) 7191-7196.

[76] J. Stadler, T. Schmid, R. Zenobi, Nanoscale Chemical Imaging Using Top-Illumination TipEnhanced Raman Spectroscopy, Nano Lett, 10 (2010) 4514-4520.

[77] E. M. van Schrojenstein Lantman, T. Deckert-Gaudig, A. J. G. Mank, V. Deckert, B.M. Weckhuysen, Catalytic processes monitored at the nanoscale with tip-enhanced Raman spectroscopy, Nature Nano, 7 (2012) 583-586. 